Portland State University

PDXScholar

1976

\title{
A Study of the Relationship between Articulation Proficiency and Auditory Conceptualization Ability
}

\author{
Alana Fenwick Bradley
}

Portland State University

Follow this and additional works at: https://pdxscholar.library.pdx.edu/open_access_etds

Part of the Speech and Hearing Science Commons, and the Speech Pathology and Audiology Commons

Let us know how access to this document benefits you.

\section{Recommended Citation}

Bradley, Alana Fenwick, "A Study of the Relationship between Articulation Proficiency and Auditory Conceptualization Ability" (1976). Dissertations and Theses. Paper 2426.

https://doi.org/10.15760/etd.2423

This Thesis is brought to you for free and open access. It has been accepted for inclusion in Dissertations and Theses by an authorized administrator of PDXScholar. For more information, please contact pdxscholar@pdx.edu. 
AN ABSTRACT OF THE THESIS OF Alana Fenwick Bradley for the Master of Science in Speech Communication with an emphasis in Speech Pathology/ Audiology presented June 7, 1976.

Tịtle: A Study of the Relationship Between Articulation Proficiency and Auditory Conceptualization Ability.

APPROVED BY MEMBERS OF THE THESIS COMMITTEE:

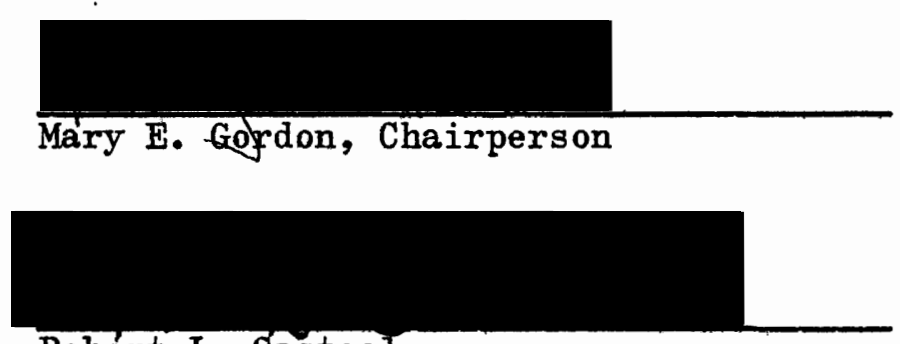

Robert L. Castee1
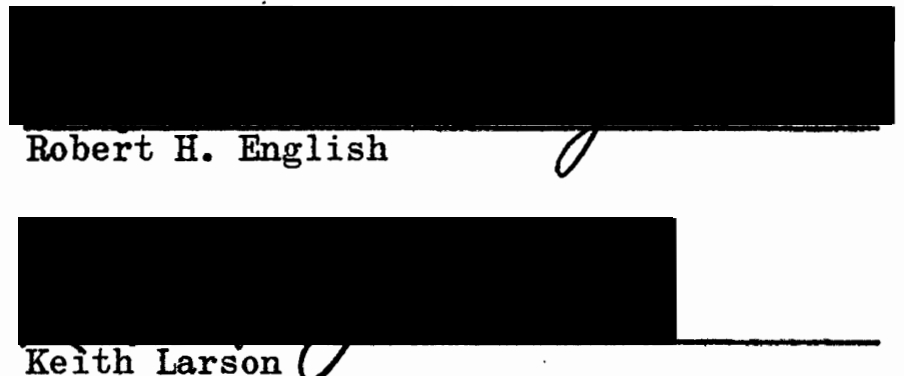

This investigation compared the auditory conceptualization ability (Lindamood and Lindamood, 1970) or vocal phonics (Van Riper, 1963) of third grade students with and without articulation deficits in an attempt to determine if a relationship exists between auditory conceptualization ability and articulation ability. The specific question posed was: Is there a statistically significant difference in auditory 
conceptualization ability between third grade children with various degrees of articulation deficits and third grade children without articulation deficits?

Thirty-two third grade students were randomly chosen from the Molalla and Colton Elementary Schools of Oregon. Each subject in the investigation was evaluated during one 20 to 25 minute session. All subjects had normal hearing acuity as determined by a hearing acuity screening test. The Photo Articulation Test (PAT) (Pendergast et al., 1965) was administered to determine articulation proficiency and the Lindamood Auditory Conceptualization Test (LAC) (Lindamood and Lindamood, 1971) was administered to determine auditory conceptualization or vocal phonics ability.

Two groups, a control and an experimental, were chosen according to the results of the PAT. The control group was comprised of 16 children with a mean age of 9.0 years displaying no phoneme errors. The experimental group consisted of 16 children with a mean age of 9.0 years displaying one or more phoneme errors. The groups were matched for sex and classroom.

The IAC scores of the two groups were compared, using a onetailed $t$ test of unrelated measures. The results indicated no statistically significant difference exists between the two groups at the .05 level of significance. Additionally, the scores on the LAC for children in the experimental group with one and two phoneme errors were compared, revealing a significant difference beyond the .05 level of confidence. Those with one articulation error performed better on the LAC than those with two errors. 
In examining the data in this study, it was concluded: 1) There is no statistically significant difference in auditory conceptualization ability between children with mild articulation deficits and those without articulation deficits; and 2) there was a statistically significant difference in auditory conceptualization ability between third graders with one articulation error and those with two articulation errors; thus, one might theorize there was a trend line toward a negative correlation between the number of articulation errors and the ability to perform the tasks necessary in auditory conceptualization. 
A STUDY OF THE RELATIONSHIP BETWEEN ARTICULATION PROFICIENCY AND AUDITORY CONCEPTUALIZATION ABILITY

by

ALANA FENWICK BRADLEY

A thesis submitted in partial fulfillment of the requirements for the degree of

MASTER OF SCIENCE IN SPEECH COMMUNICATION:

with an emphasis in SPEECH PATHOLOGY/AUDIOLOGY

Portland State University

1976 
TO THE OFFICE OF GRADUATE STUDIES AND RESEARCH:

The members of the Committee approve the thesis of Alana Fenwick Bradley presented June 7, 1976.

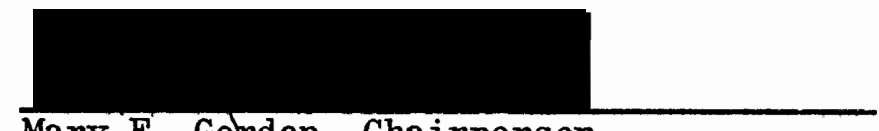

Mary E. Gofrdon, Chairperson

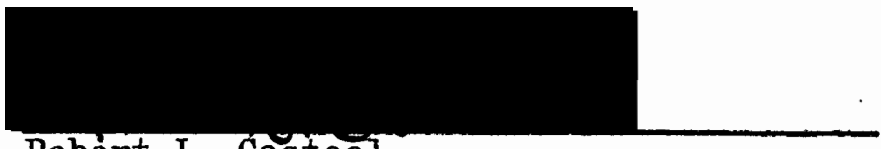

Robèrt L. Casteel
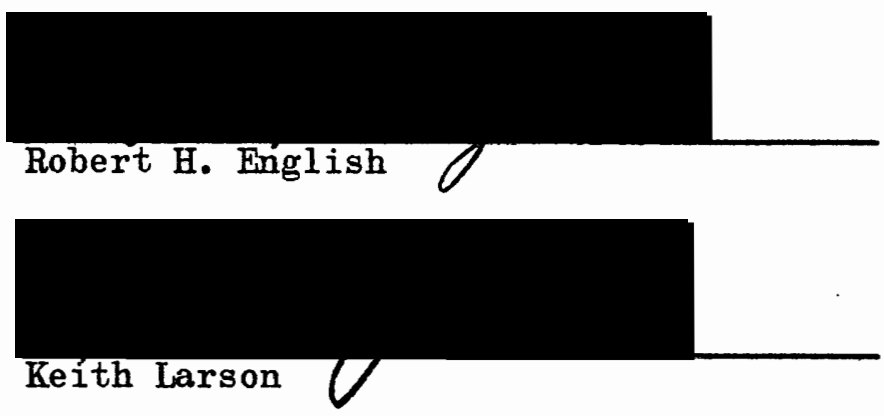

APPROVED:
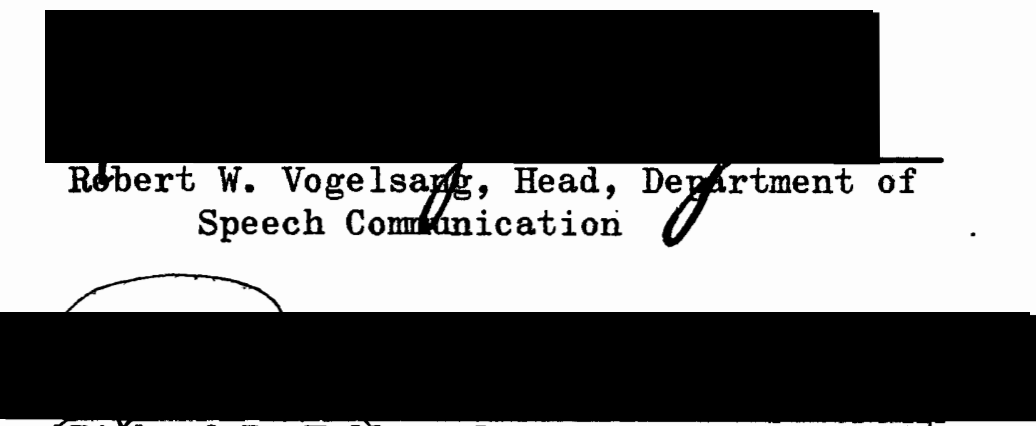
Riqhard B. Halley, Dean, Graduate Studigf
and Research 
TABLE OF CONTENTS

PAGE

ACKNOWLEDGMENTS . . . . . . . . . . . . . . . . iii

LIST OF TABLES . . . . . . . . . . . . . . . . . v vi

CHAPTER

I INTRODUCTION AND STATEMENT OF THE PROBLEM . . . . . . 1

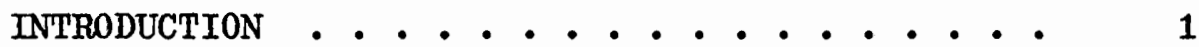

STATEMENT OF THE PROBLEM ........... 3

DEFINITIONS OF TERMS ............ 4

II REVIEW OF THE LITERATURE . . . . . . . . . . 5

AUDITORY MEMORY AND ARTICULATION PROFICIENCY • • 5

AUDITORY DISCRIMINATION AND ARTICULATION

PROFICIENCY .............. . 7

AUDITORY CONCEPTUALIZATION AND ARTICULATION

PROFICIHNCY . . . . . . . . . . 9

III METHODS AND PROCEDURES . . . . . . . . . . . . 13

METHODS . . . . . . . . . . . . . 13

Description of Subjects

Audiometric Screening

Evaluation Instrumentation

PROCEDURES . . . . . . . . . . . . .

Administration

Examiner

Scoring and Data Analysis 
CHAPTER

PAGE

IV RESULTS AND DISCUSSION OF RESULTS . . . . . . . 18

RESULTS . . . . . . . . . . . . 18

DISCUSSION OF RESULTS . . . . . . . . . 20

$\mathrm{V}$ SUMMARY AND IMPLICATIONS . . . . . . . . . . 24

STMMARY . . . . . . . . . . . . . 24

IMPLICATIONS • . . . . . . . . . . • 25

Clinical

Research

SELECTED BIBLIOGRAPHY . . . . . . . . . . . . . . . 28

APPENDICES . . . . . . . . . . . . . . . . . . 31

A LINDAMOOD AUDITORY CONCEPTUALIZATION TEST • • • • • $\quad 31$

CATEGORY I . . . . . . . . . . . . 31

CATEGORY II . . . . . . . . . . . . 32

B PARENTAL PERMISSION FORM . . . . . . . . . . 33

C PHOTO ARTICULATION TEST FORM . . . . . . . . . . 34

D TABLES FOR LAC RAW AND CONVERTED SCORES . . . . . . 35

TABLE OF LAC RAW SCORES FOR EXPERIMENTALS • • • 35

TABLE OF LAC RAW SCORES FOR CONTROLS . . . . . 36

TABLE OF LAC CONVERTED SCORES FOR EXPERIMENTALS • 37

TABLE OF IAC CONVERTED SCORES FOR CONTROLS . . . 38 


\section{LIST OF TABLES}

TABLE

PAGE

I MEANS, STANDARD DEVIATIONS, AND VALUES OF $t$

FOR LAC SCORES . . . . . . . . . . . . . . 19

II MEAN FOR CONTROL AND EXPERIMENTAL GROUPS OF

CATEGORY I AND CATEGORY II LAC CONVERTED SCORES • • 21 


\section{ACKNOWLEDGMENTS}

I wish to thank the members of my thesis committee, Mary E. Gordon, Dr. Robert L. Casteel, Dr. Robert H. English, and Dr. Keith Larson, whose comments and guidance enabled me to complete my thesis. I also thank Dr. Jack Hegrenes who counseled me on and led me through the statistics for my thesis. But most of all I extend great appreciation and admiration to Mary E. Gordon whose hard work and dedication inspired and encouraged me to complete the task.

Also, I acknowledge the cooperation and hospitality extended to me by the staffs at the Molalla and Colton Elementary Schools. I am grateful to Keith Jensen, Ken Manns, Kathy Conover, and Ralph Huntington for their help in obtaining subjects for my study. I am also grateful to the parents and children for their cooperation and enthusiasm. They made the collection of data one of the most educational and pleasurable experiences of my life.

Last but far from least, I offer my thanks and appreciation to my family. The financial and emotional support given to me by my parents was the impetus for undertaking the task at hand. Most of all I give my thanks and love to my husband, Gary, for his invaluable love, patience, understanding, and devotion over the past two and one-half years of work, sweat, and tears. 
CHAPTER I

INTRODUCTION AND STATEMENT OF THE PROBLEM

INTRODUCTION

Since the 1930s researchers in the field of speech pathology and audiology have attempted to determine which factors play a role in deficient articulation (Weiner, 1967). Many of these investigators have focused their attention on the relationship between auditory discrimination and articulation disorders, as well as between auditory memory span and articulation defects (Mange, 1960; and Metraux, 1942). Some researchers in education also have investigated the relationship of these auditory factors to reading and spelling problems (Lindamood and Lindamood, 1970). Wepman (1960) has concluded these auditory perceptual factors are positively correlated with articulation proficiency. There is, however, still much controversy and debate as to the role these auditory perceptual skills actually play in articulation. This can be seen in a reading of Weiner's (1967) critical review of the literature on the relationship between auditory discrimination and articulation.

In 1958 Van Riper and Irwin first introduced the concept of "phonetic ability or vocal phonics." They suggested perhaps it was not just auditory discrimination or auditory memory that made articulation defective but rather another auditory skill that included both of these tasks; they asserted: 
Phonetic ability involves auditory memory span and requires sound discrimination. To realize the word "nose" has three distinct sounds, $/ \mathrm{n} /, / \mathrm{o} /$, and $/ \mathrm{z} /$, and in that sequence, requires some memory and some recognition of sound characteristics. But it requires something more-the ability to perceive a temporal sequence and to recognize where each sound belongs in that sequence.

They continued by making the point that this is probably a learned behavior and that there is a good probability the individual who cannot master correct articulation has been unable to combine and analyze sound sequences (Van Riper and Irwin, 1958).

In 1963 Van Riper reasserted his hypothesis of vocal phonics:

One reason why so many children develop a jargon or gibberish is that they fail to realize that a word is made up of a series of sounds blended together. They hear the word as a whole and pronounce some sound which bears a certain likeness to it.

Lindamood and Lindamood (1970) conducted research on what they term ". . ability to conceptualize auditory patterns contrasts." This concept corresponds closely to Van Riper's vocal phonics theory. According to these researchers, identification of the number of sounds present and their sameness/difference relationship determines the ability to conceptualize sound patterns. They further asserted high performance on these tasks is important to the conceptualization of syllable units. This high performance, however, does not automatically guarantee ability to conceptualize syllable units.

The tool Lindamood and Lindamood developed and used in their research was the Lindamood Auditory Conceptualization Test (LAC) (1971), which now has been standardized (Appendix A). According to Lindamood and Lindamood, "The test consists of a series of encoding tasks similar 
to those inherent in reading and spelling." They have further asserted:

The basic perception dealt with in the LAC test will be recognized as being relevant to the development of speech and language skills. It should be a valuable diagnostic instrument in the area of speech pathology (1970).

A review of the literature reveals little or no research has been conducted in the area of speech pathology with the LAC. This investigator, therefore, felt that further study was needed to determine the relationship between articulation proficiency and the auditory ability which has been termed "phonetic ability," "vocal phonics," "auditory conceptualization," and "sound-blending" by various authors (Lindamood and Lindamood, 1970; Van Riper, 1963; and Van Riper and Irwin, 1958). Such information could aid speech pathologists in their treatment program for children with articulation deficits if they do show a deficit in auditory conceptualization skills. Articulation management then could be directed toward improvement in auditory conceptualization abilities in order to facilitate correction of the articulation deficit.

STATEMENT OF THE PROBLAM

This study sought to determine the relationship between auditory conceptualization ability and articulation ability of third graders. The specific question investigated was: Is there a statistically significant difference in auditory conceptualization ability between third grade children with various degrees of articulation deficits and third grade children without articulation deficits? 
DEFINITIONS OF TERMS

Following are definitions of terms used operationally in this study:

Articulation deficit: the judgment made about an individual's speech due to omission, substitution, and/or distortion of speech sounds.

Auditory conceptualization: the ability to perceive variations of the order of sounds within a pattern (Lindamood and Lindamood, 1971); to be used interchangeably with vocal phonics.

Auditory discrimination: the ability to distinguish between speech sounds (Weiner, 1967).

Auditory memory: the ability to retain and recall auditory stimuli (Morency, 1967).

Auditory pattern: the sequence of speech sounds in syllables and in words (Lindamood and Lindamood, 1971).

Normal articulation: the ability to correctly produce speech sounds.

Vocal phonics: the ability to perceive a temporal sequence and to recognize where each sound belongs in that sequence (Van Riper, 1963); to be used interchangeably with auditory conceptualization. 
CHAPTER II

REVIEW OF THE LITERATURE

The literature dealing with articulation disorders is vast. The relationship of deficiencies in auditory perceptual skills to articulation proficiency is one area which has been extensively investigated. This review will be limited specifically to literature relative to the relationship of articulation proficiency to auditory conceptualization ability. It should be reiterated that auditory conceptualization involves auditory discrimination and auditory memory abilities, as well as the ability to sequence sounds (Lindamood and Lindamood, 1971; and Van Riper and Irwin, 1958).

\section{AUDITORY MEMORY AND ARTICULATION PROFICIENCY}

An examination of studies conducted concerning the relationship between auditory memory and articulation ability shows no causal relationship has been consistently demonstrated. Winitz (1969) reviewed seven studies conducted with children (Clark, 1959; Hall, 1938; Mase, 1946; Metraux, 1942; Prins, 1962; Reid, 1947; and Smith, 1967) and found four reported significant differences in favor of an existence of a causal relationship (Clark, 1959; Metraux, 1942; Prins, 1962; and Smith, 1967); the other three found no significant differences (Hall, 1938; Mase, 1946; and Reid, 1947). He concluded further research is needed in this area before definitive statements can be made about the 
relationship between auditory memory and articulation skills.

Hendon (1966) reviewed four studies dealing with the relationship between auditory memory and articulation ability (Anderson, 1953; Cabrini, 1963; Gillespie, 1961; and Powers, 1957). Similar to Winitz (1969) she concluded: "Generally, it appears that a definite causal relationship between auditory memory and articulation ability has not been consistently supported or rejected."

In 1974 Glaser, Burke-Thompson, and Fenton conducted a study of 301 children, ranging in age from 4 to 10 years, to compare the short term auditory memory span ability of normal and articulation impaired children. To test auditory memory span, they presented seven strings consisting of seven words, all of which were consonant-vowel-consonant (CVC) nouns selected from a phonetically balanced (PB) word list. These strings of words were then presented to the subjects in a controlled environment. The investigators found no difference in auditory memory span ability between the speech impaired group and the normals. They did find, however, that the ability to auditorily remember strings of words increases with age.

As early as 1944 Metraux undertook the task of developing norms for auditory memory span of speech sounds for children. She prefaced her study by pointing out that current evidence available indicated the existence of memory spans for different types of material, rather than a general memory span. She further asserted most investigators believe memory span increases with age. The subjects for Metraux's study consisted of 414 school children ranging in age from 4.6 to 12.5 years. To test auditory memory for sounds she presented each child with a 
series of phonemes on a record. Her findings indicated auditory memory gradually increases with age, peaking at 10 years of age for vowels and 12 years for consonants.

Many speech pathologists and audiologists agree that auditory memory is necessary. to develop speech and language (Berry and Eisenson, 1956; Perkins, 1971; and Winitz, 1969). The review conducted by the present investigator generally shows, however, the exact relationship between articulation and auditory memory is somewhat obscure. As Metraux suggested, auditory memory of certain stimulus types, e.g., phonemes, is related to articulation proficiency.

\section{AUDITORY DISCRIMINATION AND ARTICULATION PROFICIENCY}

Lindamood and Lindamood (1971) and Van Riper and Irwin (1958) emphasized there is a close relationship between auditory memory and auditory discrimination. Before an individual can discriminate between phonemes, he must be able to remember the phonemes which were presented to him. Several studies dealing with auditory discrimination have been conducted. The following section of this review deals mainly with those studies done on the relationship between auditory discrimination and articulation proficiency.

Winitz (1969) reviewed the literature relative to the possible relationship between auditory discrimination and articulation, and concluded the results are inconsistent. He does make the point, however, that the majority of research done in this area fails to take into account that children with articulation defects produce other sounds correctly; he has stated: 
Although it has been recognized that individuals with functional articulatory errors make many correct sounds and that many of the "incorrect" sounds are uttered correctly in some contexts, some speech pathologists have continued to assume that the discrimination deficit is a general rather than a specific one. Accordingly, articulatory defective subjects have, for the most part been studied as a group without regard to the specific sounds in error.

In 1967 Weiner conducted an extensive review and analysis of previous research relative to the relationship between auditory discrimination and articulation proficiency. He asserted that the inconsistency in the results of these studies may be due to their varying designs. He further explained the differences occur because of the different methods used to assess auditory discrimination, the different definitions and measurements of articulation defect, and the different age groups studied.

In this critical review (Weiner, 1967), however, he found some hypotheses relative to auditory discrimination were supported by the research evidence. One such hypothesis is: Auditory discrimination does develop progressively no matter which test is used to measure it. Another hypothesis asserted to be accurate is: During the developmental period girls are better able to auditorily discriminate than boys. In this review of the literature the most important conclusion reached by Weiner (1967) was:

- . the evidence does support the hypothesis of a link between auditory discrimination and articulation defects. This relationship seems to hold in the primary grade age group, i.e., until about 8 or 9 years of age. . . The strongly positive findings when groups with extreme differences in articulation accuracy are compared give support to the possibility that the relationship is negligible where errors are few or nonexistent, but highly meaningful where the articulation defect is sizeable. 
Although there is still controversy about the types of relationships that may exist between auditory discrimination and articulation proficiency, it appears it can be stated a relationship is present.

\section{AUDITORY CONCEPTUALIZATION AND ARTICULATION PROFICIENCY}

Few studies deal with the relationship between auditory conceptualization ability and articulation proficiency. Those that have been conducted have focused on reading ability and then from the results have drawn conclusions about articulation ability.

In 1966 Hendon attempted to assess the basic auditory skills related to both articulation and reading ability, i.e., auditory memory span, auditory discrimination, and vocal phonic synthesis (auditory conceptualization). She believes this research was necessary to determine why so many children with reading problems also have speech deficits. She theorized these children must be manifesting an inadequacy of some common perceptual factors influencing both reading and articulation.

Hendon (1966) tested four groups: 1) functional articulatory defective; 2) retarded reading; 3) functional articulatory defectiveretarded reading; and 4) normal. These groups were derived from forty children who were eight years of age and matched for intelligence. Socioeconomic status was not controlled. They were tested for auditory memory span, auditory discrimination ability, and vocal phonic synthesis. Results of this study indicated: ". . the mean vocal phonic synthesis scores of the normal population are superior to those of the reading, articulation, and articulation-reading populations." From the 
results Hendon asserted that all children with speech and/or reading problems should be evaluated for their vocal phonic ability in order to apply the appropriate therapeutic techniques.

Goldman and Dixon (1971) discussed vocal phonics in terms of poor listening skills and believed the lack of good listening skills could be considered a primary etiological factor in misarticulation. These two investigators conducted a study in which they compared the soundblending abilities of a normal and an articulatory deviant sample. It was found the articulation defectives' scores were lower; however, the investigators could not be certain vocal-phonic disability was an etiological factor.

As early as 1955 Van Riper and Butler were describing the theory of vocal phonics, in addition to self-hearing skills, to remediate deficiencies in these auditory perceptual abilities. They stated: "We have found that one of the quickest and best ways of getting children to hear themselves talk is through training in vocal phonics." Van Riper and Butler (1955) further indicated that when a child says "wabbit" for "rabbit," it is due to his inability to hear his own error and to perform the necessary analysis and synthesis on the sound sequence. They suggested specific activities and games for the classroom teacher and/or speech clinician.

One such game is "Finger Phonics" in which the teacher/clinician asks the children to point to the object she names. The teacher/clinician then says a word, breaking it up into individual phonemes, e.g., fff-lll-or /floor/. In their book Van Riper and Butler (1955) give several additional specific activities that can be used to facilitate 
skills in vocal phonics.

Later in 1963 Van Riper discussed the theory of vocal phonics, contending this skill is learned by children through vocal play with rhymes and punning. Van Riper (1963) concluded:

It is astounding to observe how a very few sessions of this vocal play will improve the young child's speech. Until the child knows one sound from another, and until he can analyze or synthesize words, he can hardly be expected to correct himself.

The researchers who appear to have done the most in exploring auditory conceptualization are Lindamood and Lindamood. Their studies (1970 and 1971), however, have dealt with reading and spelling from which they have made inferences about speech. Their major work was with 660 children in grades $K-12$ (Lindamood and Lindamood, 1970). All subjects were given the Lindamood Auditory Conceptualization Test. It was concluded auditory conceptualization ability is a function of age, individuals with higher scores tend to be better readers and spellers, and individuals reading and/or spelling significantly below grade level are consistently poorer in auditory conceptualization ability. From these results and the literature indicating a possible existence of a vital link between reading, writing, and speech, Lindamood and Lindamood (1970) concluded auditory conceptualization (as defined by this author) is the most critical factor in this link.

Zedler (1956) conducted a study stressing the importance of the speech correctionist and the classroom teacher supplementing each other's work in order to facilitate better word synthesis skills. She pointed out that a lot of children with speech deficits also are inadequate spellers. 
Zedler (1956) developed a series of instructional materials called Teaching with Tommy Stories. These materials emphasized 1) place and manner of sound production, 2) identifying familiar sounds in the environment with their source, 3) sounding out words, 4) position of sounds in words, and 5) phoneme/grapheme association. She then conducted an investigation, using these materials, to determine if they would improve word synthesis ability, and found improvement in both spelling and articulation with the use of direct training on phonic synthesis.

From a review of the above literature it can be seen that some research investigating the relationship between auditory conceptualization and articulation deficits has been done. It is limited, however, and has been usually done as a sideline to reading and/or spelling ability. Thus, it would seem appropriate to investigate this relationship further by focusing on the articulation proficiency of children. 
CHAPTER III

METHODS AND PROCEDURES

METHODS

Description of Subjects

The sample for this investigation consisted of 32 third grade students from the Molalla and Colton Elementary Schools in Oregon. These subjects were divided into experimental and control groups. Each experimental subject was matched with a control subject of the same sex and classroom. The experimental group was comprised of 16 subjects with articulation deficits whose ages ranged from 8.7 to 10.2 years with a mean age of 9.0 . The control group consisted of 16 subjects with normal articulation ability whose ages ranged from 8.8 to 9.8 years with a mean age of 9.0. All subjects in both groups displayed normal hearing acuity. Written permission from the parents of all subjects was obtained prior to participation in the investigation (Appendix B).

Excluded from this investigation were children with a history of cerebral palsy, cleft palate, brain damage, or any abnormal orofacial deformity that might possibly interfere with articulation performance. One child with a repaired cleft was eliminated from this study. The speech pathologist was working with eight of the experimental subjects for articulation deviations; however, no direct training in auditory skills had been undertaken. 
Audiometric Screening

All subjects passed a pure tone audiometric sweep screening test at $25 \mathrm{~dB}$ (ISO) for the frequencies of $250 \mathrm{~Hz}$ and $500 \mathrm{~Hz}$, and $20 \mathrm{~dB}$ (ISO) for the frequencies of $1,000 \mathrm{~Hz}, 2,000 \mathrm{~Hz}, 4,000 \mathrm{~Hz}$, and $6,000 \mathrm{~Hz}$ bilaterally. At Molalla Elementary School the testing took place in a quiet conference room adjacent to the office. At Colton Elementary School the testing took place in a quiet room contiguous to the library. In both instances the majority of the audiometric testing occurred during morning hours to avoid outside recess noise. Four potential experimental subjects were eliminated from this investigation due to failure to pass the audiometric screening test.

Additionally, subjects were reported not to have had a history of ear impairments within the last six months. This information was obtained from the parents by including the following question on the permission forms: Has your child complained of frequent or continuous earaches in the past 6 months? Six children were eliminated prior to testing because of ear difficulties reported by their parents.

Evaluation Instrumentation

Audiometric Equipment. A portable Maico MA-16, serial number 12277, was used to conduct the audiometric'screening of the subjects in this investigation.

Articulation. The Photo Articulation Test (PAT) (Pendergast et al., 1965) was administered to all subjects in this investigation (Appendix C). The subjects were divided into two groups based upon performance on the articulation test. Those subjects with one or more 
errors were placed in the experimental group and those without articulation errors were placed in the control group. An articulation error was defined as a misarticulation of a specific phoneme in the initial, medial, and/or final position of the word as elicited by the PAT.

The PAT contains seventy-two colored photographs which are used to elicit a sample of the child's articulation ability in words. Each photograph is intended to stimulate the use of at least one consonant and sometimes one vowel or diphthong. All of the consonant sounds were tested in the initial, medial, and final positions of words. The test was developed by Pendergast and others in 1960 and standardized on 3,000 elementary school children from the Seattle, Washington, area, whose ages ranged from 3.0 to 12.0 years. On the average the total administration time is five minutes (Packouz, 1975).

Auditory Conceptualization. To assess auditory conceptualization ability, the Lindamood Auditory Conceptualization Test (LAC) (Lindamood and Lindamood, 1971) was administered to all subjects in this study. The LAC consists of two categories: 1) Category I assesses an individual's ability to perceive and discriminate individual sounds in a sequence; and 2) Category II tests an individual's ability to determine sounds and perceive their order within a syllable pattern. Each category contains a series of verbal commands intended to elicit a nonverbal response from the subject tested. The verbal stimulus in Category $I$ is, e.g., "Show me /p p p/." In Category II the verbal stimulus is, e.g., "If that says/ip/ show me/pi/." The test items in both categories increase in difficulty. Responses are in the form of manipulation of 18 colored blocks, i.e., 6 colors, 3 of each color, that are representa- 
tive of various phonemes.

The LAC was developed in 1970 by Lindamood and Lindamood in an effort to test an individual's encoding skills. These encoding skills are similiar to the ones required for reading and spelling. It was standardized on 712.randomly selected students from kindergarten through the twelfth grade in Monterey, California. Lindamood and Lindamood (1971) stated: ". . . the test-retest reliability between Form $A$ and Form B was +.96 indicating that reliability and stability are high." The validity of the test for prediction has been matched with the reading and spelling subtests of the Wide Range Achievement Test (Jastak, 1965).

\section{PROCEDURES}

\section{Administration}

All subjects in this study were assessed by the investigator for auditory acuity, articulation proficiency, and auditory conceptualization ability. The testing was conducted in a quiet room, as described earlier, with the examiner and one subject present at a time. First, the subject's auditory acuity was screened. Next, the PAT was administered to determine the subject's articulation proficiency. Finally, the subject was given the LAC in accordance with standard procedure. The testing took place in one session. and was approximately 20 to 25 minutes in length. 
Examiner

The examiner was a Master's candidate in speech pathology with over 200 supervised practicum hours in diagnosis and treatment of a variety of speech and language disorders.

Scoring and Data Analysis

The IAC was scored according to the manual of instructions. The mean and standard deviations of the converted scores were calculated for both the experimental and control groups to compare their performance on the LAC. A one-tailed $t$ test for unrelated measures was used to determine the degree of difference in performance between the two groups. This statistical measure was chosen because of Van Riper's (1963) clinical experience showing children with articulation deficits were also deficient in vocal phonics and Hendon's (1966) research, which supported Van Riper's clinical impressions. The same procedures were used to evaluate the differences existing between the LAC scores within the experimental group. 
CHAPTER IV

RESULTS AND DISCUSSION OF RESULTS

RESULTS

This study was undertaken to determine if a relationship exists between articulation ability and auditory conceptualization ability of third grade students. The specific question asked was: Is there a statistically significant difference in auditory conceptualization ability between third grade children with various degrees of articulation deficits and third grade children without articulation deficits?

Performances on the Lindamood Auditory Conceptualization Test (LAC) (Lindamood and Lindamood, 1971) were compared for two groups of children: a control group who demonstrated no articulation errors on the Photo Articulation Test (PAT) (Pendergast et al., 1965) and an experimental group who demonstrated one or more phoneme errors on the PAT. Additionally, the performances on the IAC were contrasted between the experimental group on the basis of number of phoneme errors. (See Appendix D for LAC raw and converted scores with specific articulation errors for each subject.)

The means and standard deviations of the LAC scores were calculated for the control group, the experimental group, and the subdivisions within the experimental group (Table I). A one-tailed $t$ test for unrelated measures was used to determine if the difference in performance between the groups was statistically significant. When comparing 
TABLE I

MEANS, STANDARD DEVIATIONS, AND VALUES OF $\underline{t}$ FOR LAC SCORES

\begin{tabular}{cccc}
\hline Group & Mean & S.D. & t Value \\
\hline Control $(\mathrm{N}=16)$ & 79.37 & 14.97 & \\
Experimental $(\mathrm{N}=16)$ & 73.5 & 16.45 & 1.057 \\
1 Phoneme error $(\mathrm{N}=8)$ & 79.87 & 10.48 & $1.772^{*}$ \\
2 Phoneme errors $(\mathrm{N}=7)$ & 71.42 & 16.26 & \\
3 Phoneme errors $(\mathrm{N}=1)$ & 37.00 & - & \\
\hline * $\mathrm{p}<.05$
\end{tabular}

the experimental and control groups (d.f. = 30), a $\underline{t}$ value of 1.057 was found, which is not statistically significant at the .05 level of probability. A significant difference in auditory conceptualization skills between the two groups, therefore, was not shown. In comparing the experimental subjects who displayed one phoneme error with those who had two phoneme errors, the $t$ test indicated a statistically significant difference beyond the .05 level of confidence (d.f. $=13 ; \underline{t}=$ 1.771786). The mean LAC scores shown in Table I demonstrate the subjects with only one articulation error achieved higher auditory conceptualization scores than those with two errors.

These results show no statistically significant difference exists between auditory conceptualization ability in third grade children with mild to moderate articulation deficits and those without articulation deficits. It does indicate, however, the possible existence of a 
statistically significant relationship between number of phoneme errors and auditory conceptualization ability.

\section{DISCUSSION OF RESULTS}

The data in this study suggest there is no statistically significant difference in auditory conceptualization ability between third grade children with mild articulation errors and those without articulation errors. The data does show, however, that auditory conceptualization ability might possibly differ relative to the number of phoneme errors demonstrated by a child with an articulation deficit.

It appears to this investigator that several factors lead to the above results. First, in attempting to obtain subjects for the investigation, few third graders with severe articulation deficits (five or more phoneme errors) were available. Only one child with a moderate articulation deficit of three errors was included in the sample for this study. Perhaps, a difference between the two groups would have been shown if the experimental group had been comprised of children with more severe articulation disorders. Those who did display more deviant articulation failed to pass the sweep hearing screening. None of those who failed had been previously identified by the speech clinicians as being hearing impaired, although they had been identified as articulation disordered. This suggests more care needs to be taken in assessing the hearing acuity of children displaying articulation deficits.

In looking at the child who demonstrated three articulation errors, it was observed that he' readily performed the tasks of auditory 
discrimination required on Category $I$ but was unable to perform the vocal phonics tasks required on Category II of the LAC (Appendix D, Subject 16). This limited observation tends to agree with Lindamood and Lindamood (1971) that the ability to auditorily discriminate between sounds does not automatically insure the ability to integrate and sequence them correctly. It also lends some support to Van Riper's (1963) assertion that many children use deviant articulation because of their inability to recognize that a word is made up of a series of sounds blended together. The other subjects in this study did not show such a high degree of difference in their performance between Categories I and II; however, a slightly lower mean score on Category II was noted for the experimental subjects (Table II).

\section{TABLE II}

MEAN FOR CONTROL AND EXPERIMENTAL GROUPS OF

CATEGORY I AND CATEGORY II

LAC CONVERTED SCORES

\begin{tabular}{ccc}
\hline Group & $\begin{array}{c}\text { Mean } \\
\text { Category I }\end{array}$ & $\begin{array}{c}\text { Mean } \\
\text { Category II }\end{array}$ \\
\hline Control $(\mathrm{N}=16)$ & 25.75 & 53.63 \\
Experimental $(\mathrm{N}=16)$ & 25.20 & 47.94 \\
1 Phoneme error $(\mathrm{N}=8)$ & 26.75 & 53.13 \\
2 Phoneme errors $(\mathrm{N}=7)$ & 24.28 & 47.14 \\
3 Phoneme errors $(\mathrm{N}=1)$ & 25.00 & 12.00 \\
\hline
\end{tabular}


Further evaluation of the data reveals a slight difference between the mean scores of the controls and the normative data provided by Lindamood and Lindamood (1971) for third graders. Their norm for the first half of the third grade was 71 and for the second half of the year was 81 . In this investigation the mean for the controls was 79 , which places them very close to the normative sample for the second half of the year. This tends to indicate similar auditory conceptualization skills for the control subjects in this study and the normative sample of Lindamood and Lindamood (1971), even though a rural sample was used in this investigation.

In comparing the mean scores of the experimentals (73.50) with the normative data on the IAC, however, it was found the experimentals were approximately half a school year below the mean performance. It can, therefore, be stated the experimentals generally performed at a level commensurate with the first half of the third grade rather than with the second half.

The significant difference in performance between the control group and the experimental group with two phoneme errors in auditory conceptualization ability concurs with the results of Hendon's (1966) study of vocal phonic ability. She found that children deficient in auditory memory, auditory discrimination, and vocal phonic synthesis were retarded in reading and articulation. Hendon (1966) stressed the importance of evaluating children with speech problems for their vocal phonic ability in order to supply the appropriate remediation techniques. Some of these remediation techniques might include the use of the Auditory Discrimination in Depth program developed by Lindamood and 
Lindamood (1969), the Teaching with Tommy Stories developed by Zedler (1956), or the vocal phonics games suggested by Van Riper and Butler (1955).

The performance of the children with two errors and the subject with three errors on the LAC, in addition to the research done by Hendon (1966) and Zedler (1956), further supports this investigator's hypothesis: the greater the number of phoneme errors present, the less the auditory conceptualization ability. 


\section{CHAPTER V}

SUMMARY AND IMPLICATIONS

\section{SUMMARY}

This investigation compared the auditory conceptualization ability (Lindamood and Lindamood, 1970) or vocal phonics (Van Riper, 1963) of third grade students with and without articulation deficits in an attempt to determine if a relationship exists between auditory conceptualization ability and articulation ability. The specific question posed was: Is there a statistically significant difference in auditory conceptualization ability between third grade children with various degrees of articulation deficits and third grade children without articulation deficits?

Thirty-two third grade students were randomly chosen from the Molalla and Colton Elementary Schools of Oregon. Each subject in the investigation was evaluated during one 20 to 25 minute session. All subjects had normal hearing acuity as determined by a hearing acuity screening test. The Photo Articulation Test (PAT) (Pendergast et al., 1965) was administered to determine articulation proficiency and the Lindamood Auditory Conceptualization Test (IAC) (Lindamood and Lindamood, 1971) was administered to determine auditory conceptualization or vocal phonics ability.

Two groups, a control and an experimental, were chosen according to the results of the PAT. The control group was comprised of 16 
children with a mean age of 9.0 years displaying no phoneme errors. The experimental group consisted of 16 children with a mean age of 9.0 years displaying one or more phoneme errors. The groups were matched for sex and classroom.

The LAC scores of the two groups were compared, using a onetailed $\underline{t}$ test of unrelated measures. The results indicated no statistically significant difference exists between the two groups at the .05 level of significance. Additionally, the scores on the LAC for children in the experimental group with one and two phoneme errors were compared, revealing a significant difference beyond the .05 level of confidence. Those with one articulation error performed better on the LAC than those with two errors.

In examining the data in this study, it was concluded: 1) There is no statistically significant difference in auditory conceptualization ability between children with mild articulation deficits and those without articulation deficits; and 2) there was a statistically significant difference in auditory conceptualization ability between third graders with one articulation error and those with two articulation errors; thus, one might theorize there was a trend line toward a negative correlation between the number of articulation errors and the ability to perform the tasks necessary in auditory conceptualization.

\section{IMPLICATIONS}

Clinical

One of the most important implications for the speech clinician and/or the classroom teacher arising from this study is: Children with 
two or more phoneme errors should be evaluated for their vocal phonics ability. If this ability is lacking, training should be undertaken because, as Lindamood and Lindamood (1971) point out, if the skill is still absent by the third grade, it will not spontaneously develop. Hendon (1966) also found that children deficient in vocal phonics failed to spontaneously develop the skill and were retarded in reading and articulation.

As mentioned earlier, remediation techniques such as the Auditory Discrimination in Depth program (Lindamood and Lindamood, 1969), the Teaching with Tommy Stories (Zedler, 1956), or the games suggested by Van Riper and Butler (1955) could be used to facilitate auditory conceptualization ability.

An interesting and important side effect in this investigation was the discovery of articulation deficient children with hearing acuity deficits. This would suggest: Assessment of hearing acuity should become a routine evaluative measure for children who are displaying moderate to severe articulation deficits.

\section{$\underline{\text { Research }}$}

The small number of subjects available for this study with two or more phoneme errors limits the amount of generalizations that can be made based on the results. In this study, children displaying articulation deficits differed only slightly from the control group, possibly due to the number of mild and/or borderline articulation errors present. Further research with a larger sample displaying more phoneme errors is needed to compare the auditory conceptualization ability of 
children. Research at varying age levels also would be valuable and, as Winitz (1969) suggested, with children displaying specific phoneme errors.

Additional investigations assessing the growth in articulation skills in articulation defective subjects who have received training in vocal phonics skills, i.e., auditory conceptualization, also might be invaluable to the speech clinician and/or classroom teacher. Further, articulation progress of such group could be compared with the growth of a group who received articulation management and no training in vocal phonics. 


\section{SELECTED BIBLIOGRAPHY}

ANDERSON, VIRGIL A., Improving the Child's Speech. New York: 0xford University Press (1953).

BERRY, MILDRED F., and EISENSON, JON, Speech Disorders: Principles and Practices of Therapy. New York: Appleton-Century-Crofts (1956).

CABRINI, SISTER H., Auditory memory span and functional articulatory disorders in relation to reading in grade two. Journal Developmental Reading, 7, 4-28 (1963).

CLARK, R. R., Maturation and speech development, Part I. Logos, 2, 49-54 (1959).

GILIESPIE, JUDITH, The relation of articulatory adequacy, age, and certain tasks of auditory discrimination: Background. Unpublished master's thesis, Vanderbilt University (1961).

GLASER, E. R., BURKE-THOMPSON, M., and FENTON, E. R., Short term auditory memory span in normal and articulation impaired children, ages 4 to 10 years. Paper presented at the American Speech and Hearing Association meeting (1974).

GOLDMAN, RONALD, and DIXON, SARAH D., The relationship of rocal-phonic and articulatory abilities. Journal Learning Disabilities, 4, 2, 251-256 (1971).

HALL, M. E., Auditory factors in functional articulatory speech defects. Journal Experimental Education, 7, 110-132 (1938).

HENDON, MARILIN K., Auditory memory span, auditory discrimination, and vocal phonic synthesis in an articulation defective, a reading defective, an articulation-reading defective, and a normal population. Unpublished master's thesis, Vanderbilt University $(1966)$.

JASTAK, J. F., Wide Range Achievement Test Manual. (Rev.) Wilmington, Del.: C. L. Story Co. (1965).

LINDAMOOD, CHARLES H., and LINDAMOOD, PATRICIA C., Conceptualization of auditory patterns. Paper presented at the International Reading Association conference, Anaheim, Calif. (1970). 
LINDAMOOD, CHARIES H., and LINDAMOOD, PATRICIA C., The A.0.D. Program: Auditory Discrimination in Depth. Boston: Teaching Resources (1969).

LINDAMOOD, CHARLES H., and LINDAMOOD, PATRICIA C., Preliminary Manual: Lindamood Auditory Conceptualization Test. New York: Teaching Resources (1971).

MANGE, CHARLES V., Relationship between selected auditory perceptual factors and articulation ability. Journal Speech and Hearing Research, 3, 1, 67-75 (1960).

MASE, D. J., Etiology of articulatory speech defects, reported in Teachers College Contribution to Education, No. 921. New York: Columbia University (1946).

METRAUX, RUTH W., Auditory memory span for speech sounds of speech defective children compared with normal children. Journal Speech and Hearing Disorders, 7, 1, 33-37 (March, 1942).

METRAUX, RUTH W., Auditory memory span for speech sounds: Norms for children. Journal Speech and Hearing Disorders, 9, 1, 31-38 (1944).

MORENCY, ANNE, Auditory modality research and practice. Paper presented at the International Reading Association convention, Seattle (1967).

PACKOUZ, SUSAN J., Validation of the Preschool Speech and Language Screening Test. Unpublished master's thesis, Portland State University (1975).

PENDERGAST, K., DICKEY, STANLEY, SELMAR, JOHN, and SODER, ANTON, Photo Articulation Test. Chicago: The King Co. (1965).

PERKINS, WILLIAM H., Speech Pathology: An Applied Behavioral Science. St. Louis: The C. V. Mosby Co. (1971).

POWERS, M. H., Functional disorders of articulation symptomatology and etiology. In L. E. Travis (Ed.), Handbook of Speech Pathology. New York: Appleton-Century-Crofts (1957).

PRINS, T. DAVID, Motor and auditory abilities in different groups of children with articulation deviations. Journal Speech and Hearing Research, 5, 2, 161-168 (June, 1962).

REID, G., The etiology and nature of functional articulatory defects in elementary school children. Journal Speech and Hearing Disorders, 12 , 143-150 (1947). 
SMITH, C. R., Articulation problems and ability to store and process stimuli. Journal Speech and Hearing Research, 10, 348-353 (1967).

VAN RIPER, CHARLES, Speech Correction: Principles and Methods. (4th ed.) Englewood Cliffs: Prentice-Hall, Inc. (1963).

VAN RIPER, CHARLES, and BUTLER, KATHARINE G., Speech in the Elementary Classroom. New York: Harper and Brothers Publishers (1955).

VAN RIPER, CHARLES, and IRWIN, JOHN V., Voice and Articulation. Englewood Cliffs: Prentice-Hall, Inc. (1958).

WEINER, PAUL S., Auditory discrimination and articulation. Journal Speech and Hearing Disorders, 32, 1, 19-28 (1967).

WEPMAN, JOSEPH M., Auditory discrimination, speech and reading. Elementary School Journal, 60, 325-333 (March, 1960).

WINITZ, HARRIS, Articulatory Acquisition and Behavior. New York: Appleton-Century-Crofts (1969).

ZEDLER, EMPRESS Y., Effect of phonic training on speech sound discrimination and spelling performance. Journal Speech and Hearing Disorders, 21, 2, 245-250 (June, 1956). 
APPENDIX A

LINDAMOOD AUDITORY CONCEPTUALIZATION TEST

CATEGORY I

LAC TEST - FORM A

INDIVIDUAL RECORD SHEET

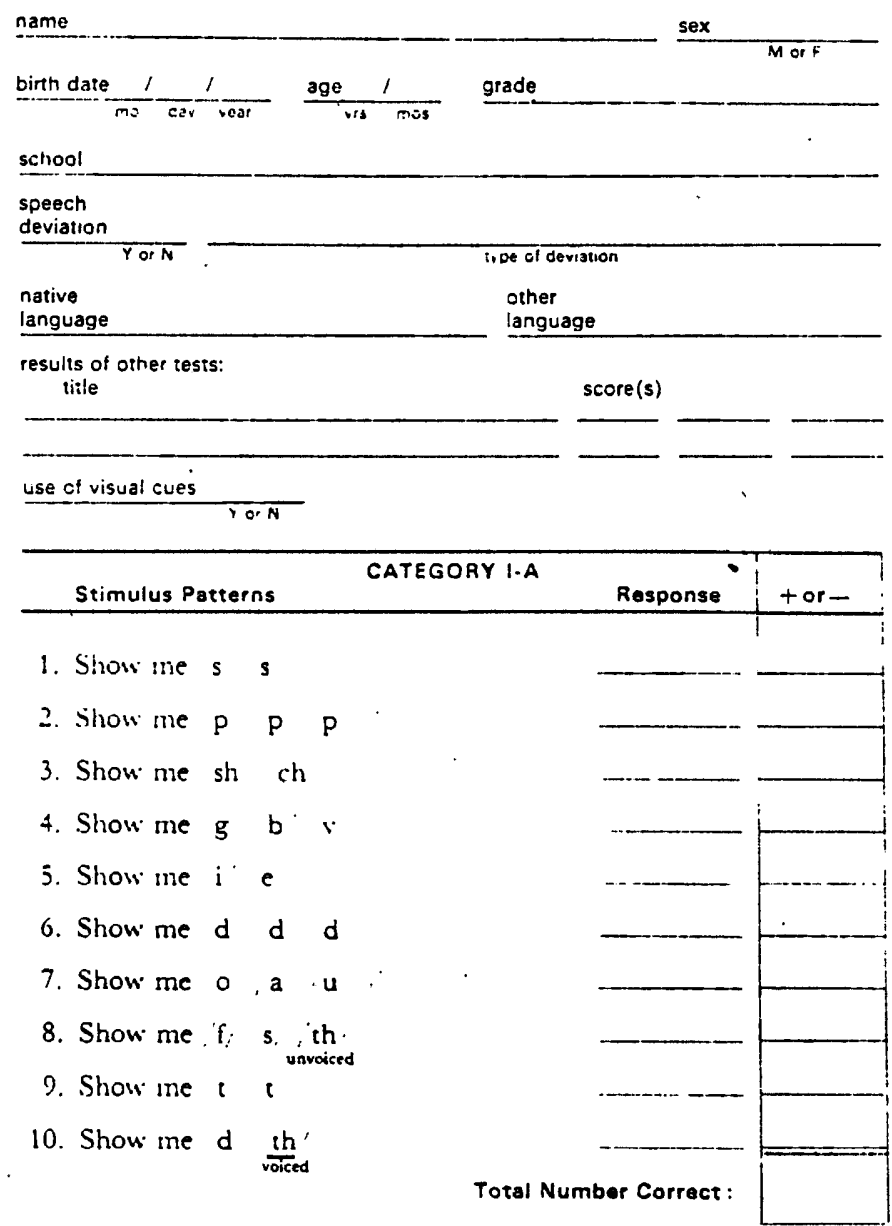

examiner

$\frac{\text { test date } \frac{1}{\text { mo. day reat }}}{\text { day }}$

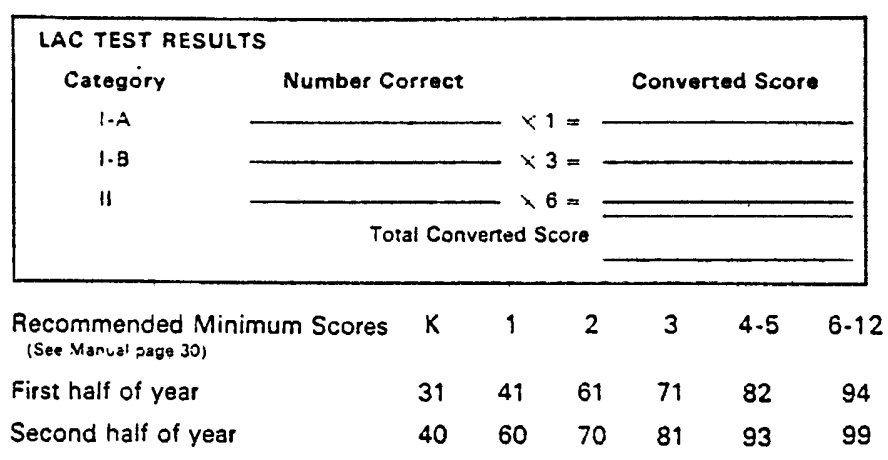

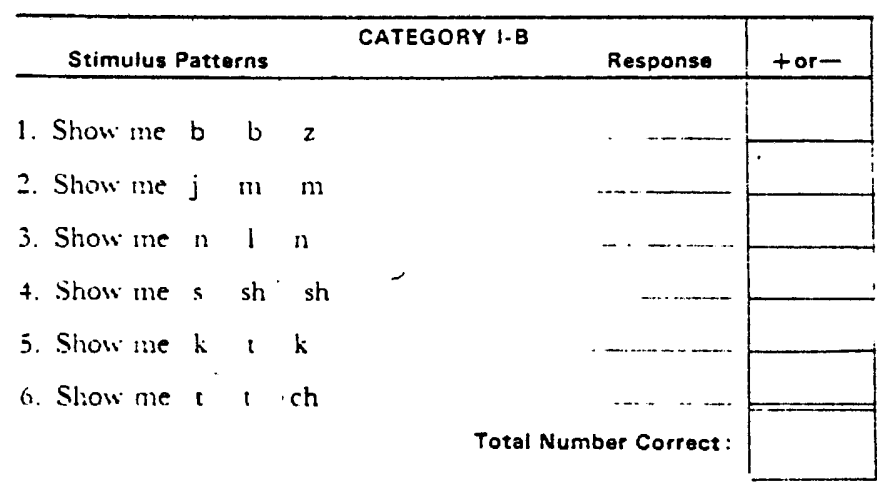

Color code: $R=$ red. $I=$ yelluw. $(i=$ green. $W=$ white. $B=$ blue. $K=$ black

(apprrach (C) TM-1 by Traching Resources (:orporituon. III rublits reselwed. Mlanufactured in the Lnited States of America. 
LAC TEST - FORM A

CATEGORY ॥

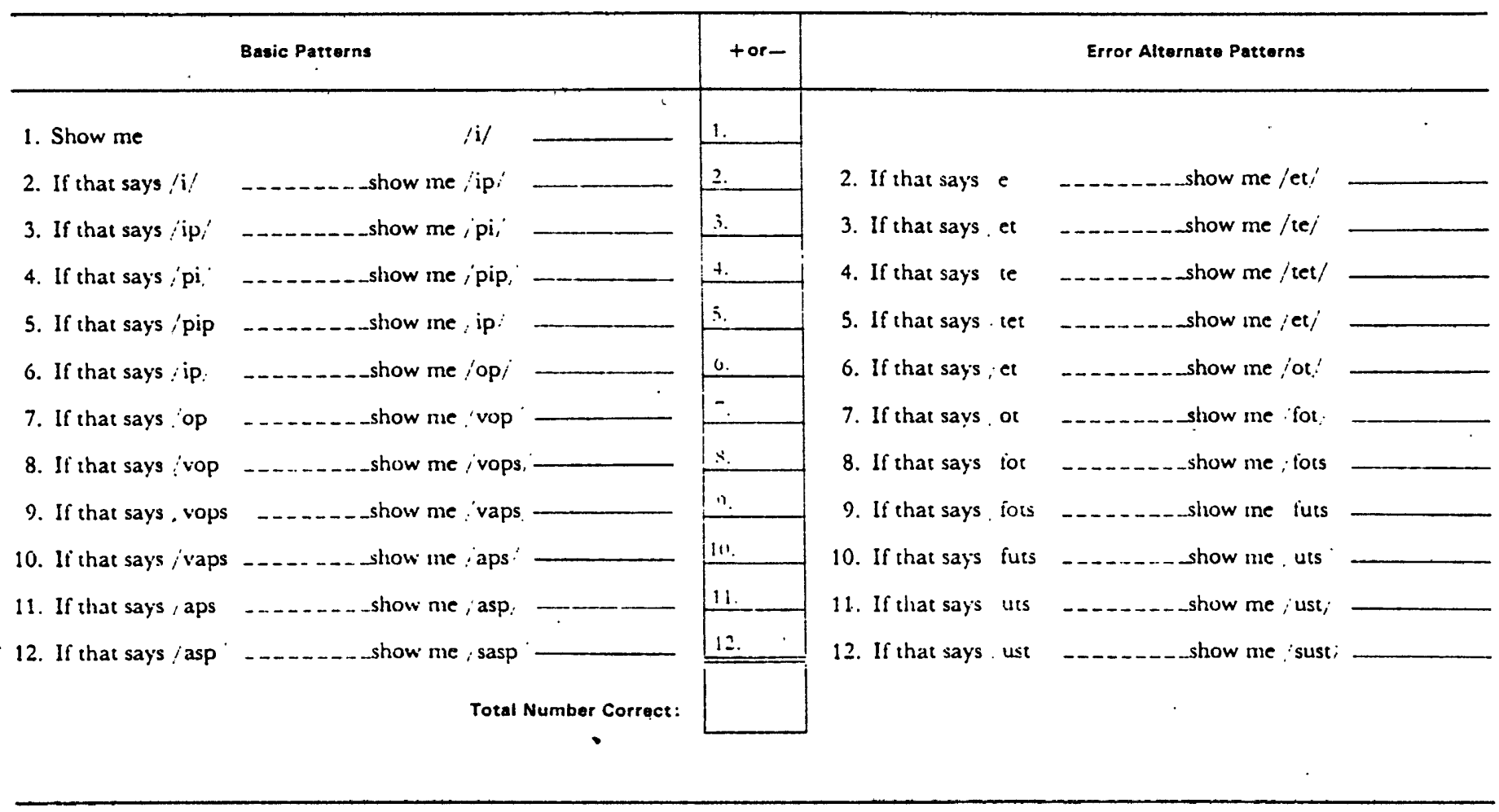

Color code: $R=$ red. $Y=$ yellow. $(r=$ green. $W=$ white. $B=$ blue. $K=$ black

If the examiner sets up the blocks for a given pattern item, it should be recorded on the dotted line.

Subject patterns should be recorded on the sulid line. 


\title{
APPENDIX B
}

\section{PARENTAL PERMISSION FORM}

\author{
KEUSST FOK PEHYISSION TO T STT
}

\begin{abstract}
jhar Parinta,
I am 3 praduate student at portland jtito University and have boen given nermission by Mr. Kleth Jensen to ather itata for a rasearch projact in tho Mollala school District. I am tastinf third prators in an attempt to find out whether tharo is a. relationst In hitwenn spoech ibility (articulation) and hanring. skills (auditory conceptualization). The results of this study ahould help the teacher and other professionals dealinp with chlidron plan proirams for childron.

This can be accomblished by tho administrition of thrae ovaluation instrumants; 1 isro tone haarinp. test, Photo Articulation Test (PAT), and the Lindamool Auditory Conceptualization Test (LAC). The Dure tone hearing test wlil simply consist of your child ralsing his hend whon he hears the tone. The PAT consists of colored photopraphis of objacts which your child will be askert to name; It measures the ch1ld's speech development. The IAC requires the child to manipulate colored blocks in response to sounds and tosts the oh!ld's abllity to distingulsh botween different sounds.
\end{abstract}

The avaluation will be done by nysolf, Alana K. Bradley and will take 15 to 30 minutes of your ch!ld:s timo. No names or other identification orocedures w1ll : u used in reporting the results of this study.

N1ll you ilense, halu na by pilling out the information bolow indicating your anproval to tast your chlld and returning it tomorrow to the school so the clissroom taachar can pive it to me.

Thank you for vour help.

Alana K. Bradloy

Griduate Student, Speech \& Hearing

Portland State Univorsity

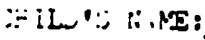
:an your child complained of freouent or continuous ear aches in the past
6 rontris?

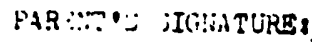

DATE: 


\section{APPENDIX C}

\section{PHOTO ARTICULATION TEST FORM}

PAT RECORDING SHEET

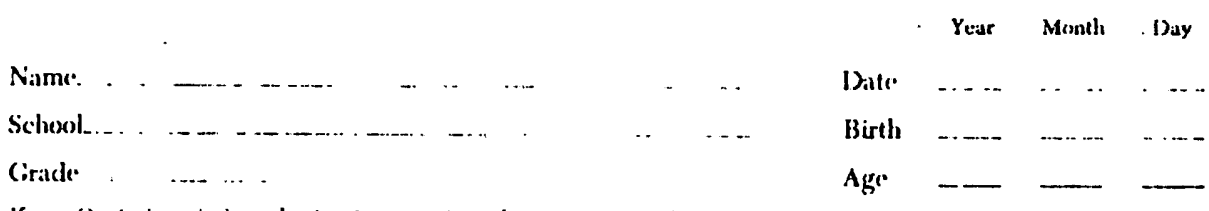

Key: Omission (-); sulestitution (write phometic symbed of sound sulstituted); severity of distortion (D1), (D2), (1)3); ability (1) imilate (circle svinbol or (error).

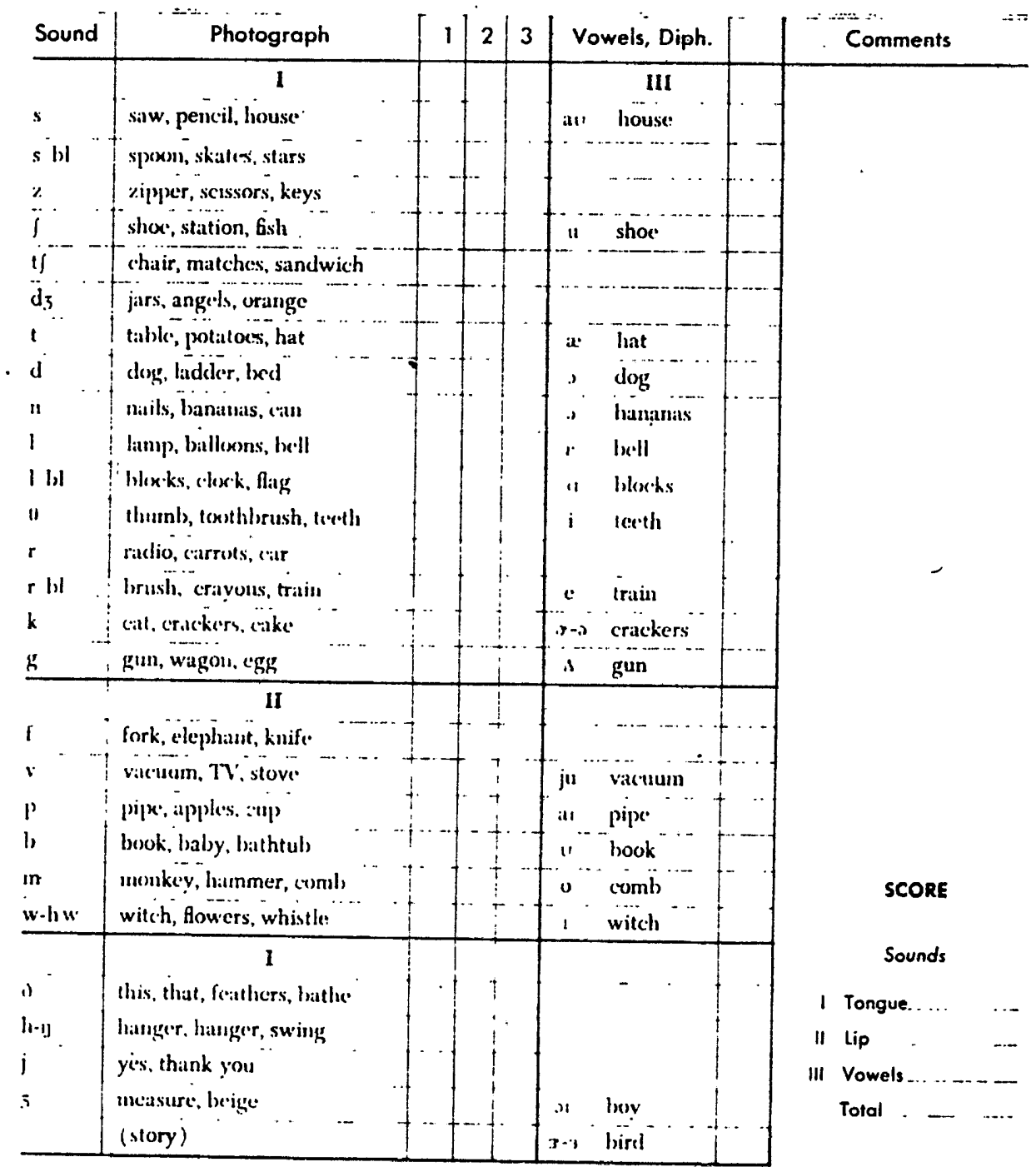




\section{APPENDIX D}

TABLES FOR LAC RAW AND CONVERTED SCORES

TABLE OF LAC RAW SCORES FOR EXPERIMENTALS

\begin{tabular}{|c|c|c|c|c|c|c|}
\hline Subject & $\begin{array}{l}\text { \# Phoneme } \\
\text { Errors } \\
\end{array}$ & $\begin{array}{c}\text { Specific } \\
\text { Articulation Errors } \\
\end{array}$ & $\begin{array}{l}\text { \# Correct } \\
\text { Category I-A }\end{array}$ & $\begin{array}{l}\text { \# Correct } \\
\text { Category I-B } \\
\end{array}$ & $\begin{array}{l}\text { \# Correct } \\
\text { Category II } \\
\end{array}$ & $\begin{array}{l}\text { Total \# } \\
\text { Correct } \\
\end{array}$ \\
\hline 1 & 1 & $/ \mathrm{s} /$ All positions & 9 & 6 & 9 & 24 \\
\hline 2 & 1 & $/ \mathrm{r} /$ All positions & 8 & 6 & 7 & 21 \\
\hline 3 & 1 & $/ \mathrm{r} / \mathrm{All}$ positions & 9 & 6 & 8 & 23 \\
\hline 4 & 1 & $/ \mathrm{s} /$ Medial and final positions & 9 & 6 & 10 & 25 \\
\hline 5 & 1 & $/ \mathbf{r} /$ Medial position & 10 & 6 & 11 & 27 \\
\hline 6 & 1 & $|\theta|$ Medial and final positions & 9 & 5 & 10 & 24 \\
\hline 7 & 1 & $/ \mathrm{s} /$ Final position & 9 & 6 & 10 & 25 \\
\hline 8 & 1 & $/ \mathrm{s} / \mathrm{All}$ positions & 10 & 6 & 5 & 21 \\
\hline 9 & 2 & $\begin{array}{l}/ \mathrm{s} / \text { Initial and final positions } \\
/ \mathrm{z} / \text { Medial and final positions }\end{array}$ & 10 & 6 & 8 & 24 \\
\hline 10 & 2 & $/ \mathrm{z} /$ Final $/ d_{3} /$ final positions & 9 & 4 & 7 & 20 \\
\hline 11 & 2 & $\begin{array}{l}/ \theta / \text { Initial and final positions } \\
/ \mathrm{v} / \text { Initial position }\end{array}$ & 8 & 5 & 3 & 16 \\
\hline 12 & 2 & $/ \mathrm{s} /$ Initial $/ \mathrm{f} /$ initial positions & 10 & 6 & 8 & 24 \\
\hline 13 & 2 & $\begin{array}{l}/ \mathrm{s} / \text { All positions }) \\
/ \theta / \text { Final position })\end{array}$ & 9 & 5 & 10 & 24 \\
\hline 14 & 2 & $\begin{array}{l}/ / \mathrm{s} / \text { All positions) } \\
/ / / \text { All positions) }\end{array}$ & 10 & 5 & 11 & 26 \\
\hline 15 & 2 & $\begin{array}{l}/ \mathrm{s} / \text { Initial and medial positions } \\
/ \mathrm{z} / \text { Final position }\end{array}$ & 9 & 4 & 8 & 21 \\
\hline 16 & 3 & $\left.\begin{array}{l}/ \mathrm{s} / \text { All positions } \\
/ / 3 / \text { Final position } \\
/ \mathrm{g} / \text { Medial and final positions })\end{array}\right\}$ & 10 & 5 & 2 & 17 \\
\hline
\end{tabular}


TABLE OF LAC RAW SCORES FOR CONTROLS

\begin{tabular}{|c|c|c|c|c|}
\hline Subject & $\begin{array}{c}\text { \# Correct } \\
\text { Category I-A } \\
\end{array}$ & $\begin{array}{c}\text { \# Correct } \\
\text { Category I-B } \\
\end{array}$ & $\begin{array}{c}\text { \# Correct } \\
\text { Category II } \\
\end{array}$ & $\begin{array}{l}\text { Total \# } \\
\text { Correct }\end{array}$ \\
\hline 1 & 9 & 6 & 11 & 26 \\
\hline 2 & 9 & 5 & 12 & 26 \\
\hline 3 & 7 & 6 & 10 & 23 \\
\hline 4 & 10 & 5 & 7 & 22 \\
\hline 5 & 8 & 5 & 7 & 20 \\
\hline 6 & 9 & 6 & 5 & 20 \\
\hline 7 & 9 & 6 & 9 & 24 \\
\hline 8 & 10 & 6 & 11 & 27 \\
\hline 9 & 9 & 5 & 11 & 25 \\
\hline 10 & 9 & 6 & 6 & 21 \\
\hline 11 & 10 & 3 & 7 & 20 \\
\hline 12 & 10 & 6 & 11 & 27 \\
\hline 13 & 10 & 6 & 12 & 28 \\
\hline 14 & 9 & 6 & 8 & 23 \\
\hline 15 & 10 & 6 & 10 & 26 \\
\hline 16 & 10 & 5 & 6 & 21 \\
\hline
\end{tabular}


TABLE OF LAC CONVERTED SCORES FOR EXPERIMENTALS

\begin{tabular}{|c|c|c|c|c|}
\hline Subject & $\begin{array}{l}\text { \# Phoneme } \\
\text { Errors } \\
\end{array}$ & $\begin{array}{c}\text { Category I } \\
\text { Score } \\
\end{array}$ & $\begin{array}{c}\begin{array}{c}\text { Category II } \\
\text { Score }\end{array} \\
\end{array}$ & $\begin{array}{l}\text { Total } \\
\text { Score }\end{array}$ \\
\hline 1 & 1 & 27 & 54 & 81 \\
\hline 2 & 1 & 26 & 42 & 68 \\
\hline 3 & 1 & 27 & 48 & 75 \\
\hline 4 & 1 & 27 & 60 & 87 \\
\hline 5 & 1 & 28 & 66 & 94 \\
\hline 6 & 1 & 24 & 60 & 84 \\
\hline 7 & 1 & 27 & 60 & 87 \\
\hline 8 & 1 & 28 & 35 & 63 \\
\hline 9 & 2 & 28 & 48 & 76 \\
\hline 10 & 2 & 21 & 42 & 63 \\
\hline 11 & 2 & 23 & 18 & 41 \\
\hline 12 & 2 & 28 & 48 & 76 \\
\hline 13 & 2 & 24 & 60 & 84 \\
\hline 14 & 2 & 25 & 66 & 91 \\
\hline 15 & 2 & 21 & 48 & 69 \\
\hline 16 & 3 & 25 & 12 & 37 \\
\hline
\end{tabular}


TABLE OF LAC CONVERTED SCORES FOR CONTROLS

\begin{tabular}{|c|c|c|c|}
\hline Subject & $\begin{array}{c}\text { Category I } \\
\text { Score } \\
\end{array}$ & $\begin{array}{c}\text { Category II } \\
\text { Score } \\
\end{array}$ & $\begin{array}{l}\text { Total } \\
\text { Score }\end{array}$ \\
\hline 1 & 27 & 66 & 93 \\
\hline 2 & 24 & 72 & 96 \\
\hline 3 & 25 & 60 & 85 \\
\hline 4 & 25 & 42 & 67 \\
\hline 5 & 23 & 42 & 65 \\
\hline 6 & 27 & 30 & 57 \\
\hline 7 & 27 & 54 & 81 \\
\hline 8 & 28 & 66 & 94 \\
\hline 9 & 24 & 66 & 90 \\
\hline 10 & 27 & 36 & 63 \\
\hline 11 & 19 & 42 & 61 \\
\hline 12 & 28 & 66 & 94 \\
\hline 13 & 28 & 72 & 100 \\
\hline 14 & 27 & 48 & 75 \\
\hline 15 & 28 & 60 & 88 \\
\hline 16 & 25 & 36 & 61 \\
\hline
\end{tabular}

